\title{
DIALÉTICA DO PARQUE AUGUSTA
}

\author{
Sérgio Júnior ${ }^{1}$
}

\author{
Ana Paula Momose Guimarães ${ }^{2}$
}

\begin{abstract}
RESUMO
Este artigo tem como objeto de análise o Parque Augusta e a tentativa de buscar configurar a dialética do conceito espaço público e espaço privado e refletir que as morosidades da efetivação das posturas públicas já consolidadas frente às mutações urbanas da cidade de São Paulo são complexas, mas que precisam ser pontuadas e efetivadas de maneira mais contundente pelo poder público. Elencando os agentes envolvidos, seus principais interesses e a legislação vigente buscaram caracterizar as diversas controversas da utilização da área pública, todavia de propriedade privada. Decorrer também na disputa de uma área bastante valorizada e a dificuldade de preservar a vegetação remanescente da Mata Atlântica são o grande desafio, e refletir sobre como interferir na complexidade do tecido urbano que vive em constante mutação.
\end{abstract}

PALAVRAS-CHAVE: São Paulo. Parque Augusta. Áreas Verdes.

\section{DIALECTIC PARK AUGUSTA}

\section{ABSTRACT}

This article analyzed the Park Augusta and sought to get set the dialectic between the concept about public space and private space and to reflect about the slow pace of execution of public attitudes already consolidated in the face of urban changing on São Paulo city, that are complex, but needs to be scored and effect in a more forceful way by the government. Linked in those agents involved, their main interests and current legislation sought to characterize the various controversial use that public area, but privately owned. Course also in contention in a very valued area and the difficulty of preserving the remaining vegetation of the Atlantic Forest is the great challenge, and reflect on it and how to interfere within complexity of the urban that used to live in constantly changing.

\footnotetext{
${ }^{1}$ Sergio possui graduação em Turismo e Arquitetura e Urbanismo, mestrando em Arquitetura e Urbanismo pela Universidade Presbiteriana Mackenzie. arquiteturismologo.sergio@gmail.com

${ }_{2}$ Ana Paula Momose Guimarães é Arquiteta e Urbanista, realizou mestrado profissionalizante em Engenharia dos Materiais atualmente é doutoranda pela Universidade Presbiteriana Mackenzie. anamomose@uol.com.br
} 


\section{DIALÉCTICA PARQUE AUGUSTA}

\section{RESUMEN}

En este artículo se analiza en el Parque Augusta y tratando de establecer la dialéctica del concepto de espacio público y el espacio privado. Y reflejan que el lento ritmo de ejecución de las actitudes del público ya consolidados en la cara de las mutaciones urbanas de la ciudad de São Paulo son complejas, pero que necesitan ser anotó y efecto de una manera más contundente por parte del gobierno. Elencando los agentes implicados, sus principales intereses y la legislación vigente tratado de caracterizar los distintos controvertido uso del espacio público, pero de propiedad privada. Curso también en la pelea en una zona muy valorada y la dificultad de preservar la vegetación remanente del Bosque Atlántico es el gran reto, y reflexionar sobre la forma de interferir con la complejidad de la trama urbana que vive en constante cambio.

\section{INTRODUÇÃO}

Este artigo busca analisar a dificuldade de se manter as áreas verdes remanescentes em localidade de grande valorização imobiliária na cidade de São Paulo, como o estudo de caso a dialética do "Parque Augusta", situado no bairro da Consolação.

A área de estudo localiza-se na região do centro, mais especificamente na rua Augusta, entre as paralelas Marquês de Paranaguá e Caio Prado (Figura 1). O terreno ocupa aproximadamente meia quadra e constitui de $23.733 \mathrm{~m}^{2}$ de área privada, grande parte, é ocupada por um bosque de vegetação remanescente da Mata Atlântica tombado pelo Conselho Municipal de Preservação do Patrimônio Histórico, Cultural e Ambiental da Cidade de São Paulo (CONPRESP) - através da Resolução 23/2004. 


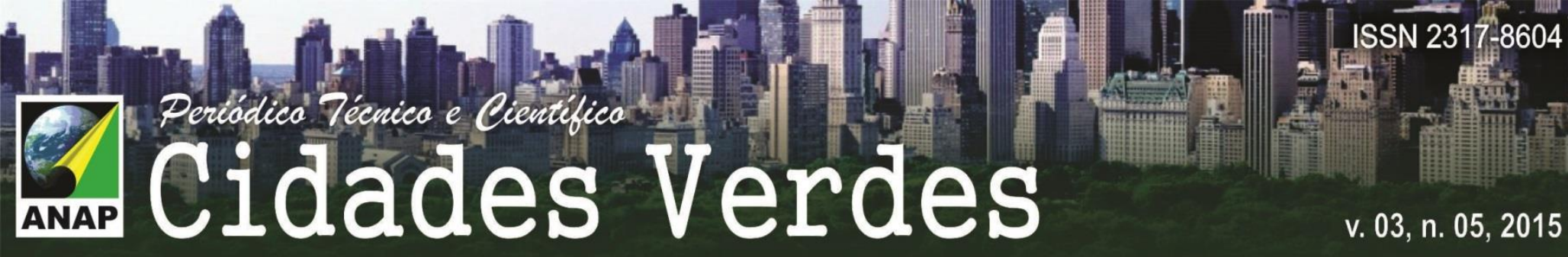

Figura 1 - Área do Parque Augusta.

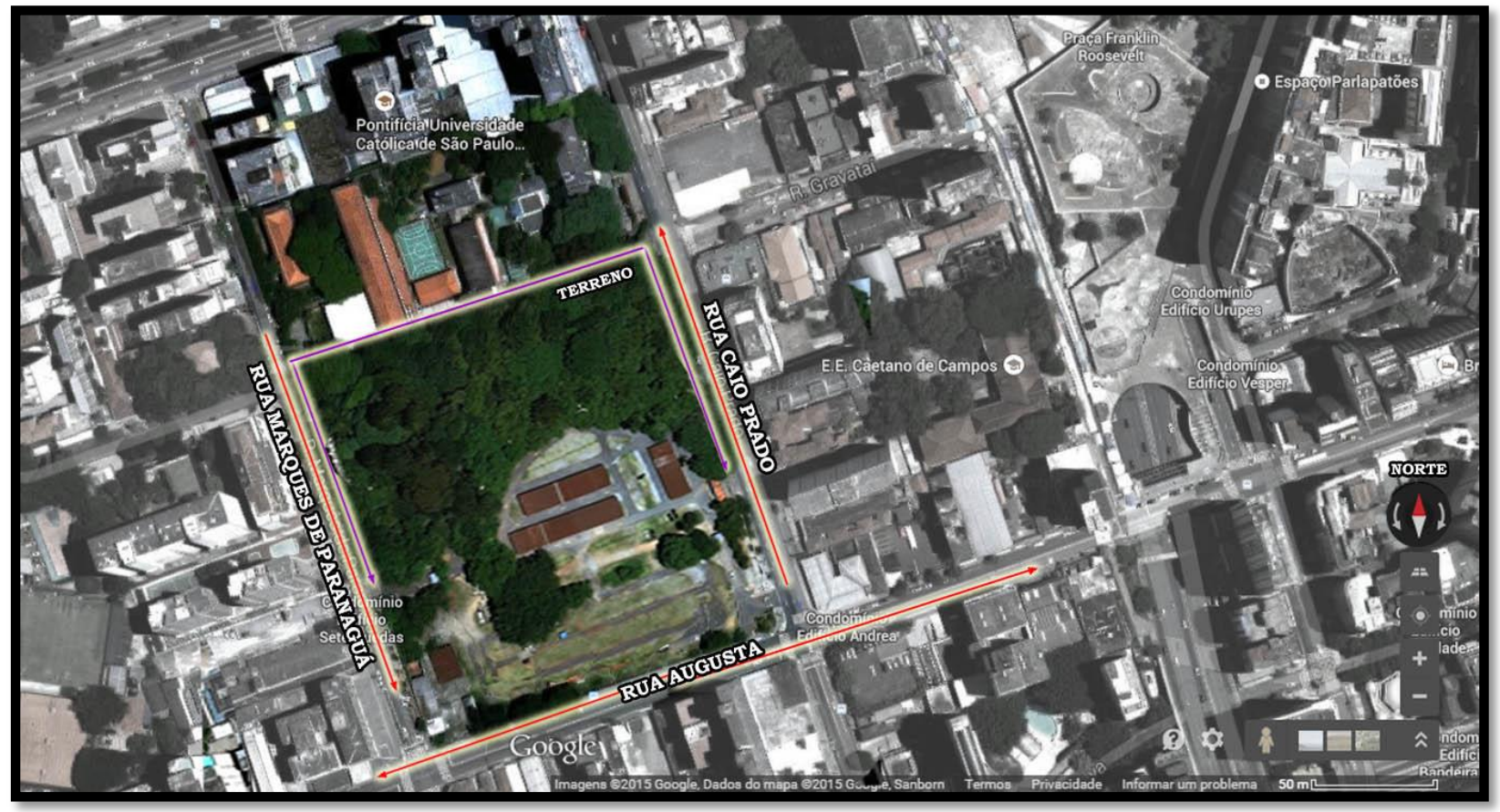

FONTE DA IMAGEM: GoogleMaps, visualização tipo satélite. EDIÇÃO: O próprio Autor.

Está área verde pertenceu a uma instituição de ensino que esteve em funcionamento até 1967, e infelizmente em 1974 houve a demolição ilegal do colégio, que na época, estava em processo de preservação ou tombamento pelo CONPRESP. Trinta e um anos se passaram e o local ainda está subutilizado. Até próximo dos anos 2000 a Rua Augusta, principal ponto de acesso ao terreno, era polo de prostituição, criminalidade e comércio de entorpecentes diversos (PISSARDO, 2013, p. 184); cabe destacar que os investidores do setor de entretenimento foram os principais responsáveis por reverter e transfigurar a imagem da rua de forma positiva, inclusive, tornou-se um dos pontos turísticos da Cidade, divulgado pelas agências: "São Paulo Convention\&Visitors Bureau" e "São Paulo Turismo (SPTuris)", enquanto sugestão de passeios a quem visita a Cidade.

Em meio a processos abrangentes de revitalização, em dezembro de 2004, consolidou-se a preservação do Bosque, em virtude da diversidade arbórea e arbustiva existente no lote que, até então, estivera anônimo ou esquecido tanto pelo setor imobiliário quanto pelos ativistas. Entretanto, a relevância deste local ou bosque para a região, atualmente, justifica-se pela escassez da permeabilidade de 
edificação e exacerbadas preocupações ecológicas; e que, apesar das mais diversas manifestações considerarem o espaço apropriado ao uso coletivo, não é garantia que estes ambientes serão convidativos ou adaptáveis à presença da população, negando, portanto, o encontro e o convívio esperado. Um impasse superior a 40 anos (O ESTADO DE S. PAULO, 19/08/2013). Alguns destes exemplos podem ser pontuados na Cidade, como as praças Roosevelt e Panamericana, frequentemente associados enquanto "elemento negativo" por desconstruir o significado que Ihes poderia ser conferido através do espaço público de convívio; em outras palavras, no caso da Roosevelt, negada socialmente pelo público que a ela frequenta, ocasionado pela homogeneização e apropriação do espaço por elementos excluídos da sociedade, fala-se de "skatistas", moradores de rua, usuários e vendedores de drogas, enfim, segmentos estes que exigem monitoria constante de segurança e fiscalização policial para torná-la permeável ao público em geral; já a Praça Panamericana, apesar de abster-se dos elementos da Roosevelt e sua localização estratégica em um bairro considerado nobre, assemelha-se a uma rotatória e é margeada por carros, em movimento e estacionados, além disso, conta com difícil acesso ao pedestre, sendo pouco atrativa e passível de visitação.

A situação assemelha-se a reportagem da av. Rio Branco que, com menos árvores e mais luz, tenta reaver brilho do passado, pois a região tem vários equipamentos importantes, porém desarticulados. Valter Caldana, professor de urbanismo do Mackenzie avalia da seguinte forma "Numa cidade inóspita, os lugares acabam se voltando para dentro; as pessoas chegam de carro e não interagem com o entorno (FOLHA DE S. PAULO, 04/05/2015)". Esta situação, também, pode ser incorporada a região do parque Augusta.

Portanto, algumas hipóteses preestabelecidas tanto pelo senso comum como pelo conhecimento científico, tidas como verdadeiras e praticamente óbvias serão testadas pela pesquisa. Hipoteticamente, na visão dos ativistas, seria importante manter este resquício de mata atlântica, em meio à "selva de concreto" de um grande centro urbano; pela ótica do poder público, "todo bem público engajado no cotidiano tanto do residente quanto do visitante, torna-se dignificante no processo 
São Paulo" o acervo online conta com exemplares desde 2010 e conta 85 publicações acerca do tema, da mesma forma, no jornal "O Estado de São Paulo", encontrou-se exemplares desde 2008 e 48 publicações até o presente momento (Abril de 2015); por fim, embasar-se nos conceitos vigentes da legislação e estabelecer um paralelo entre os interesses dos agentes sociais envolvidos e apresentar um breve discurso comparativo com o "Parque Gezi" de Istambul, Turquia, que também foi alvo de diversos protestos e lutas sociais para manter a área verde frente à construção de um shopping.

\section{Método de Análise}

Para se obter algum produto do material jornalístico, criou-se um banco de dados específico para a pesquisa contendo os seguintes campos:

- Título da publicação.

- Ano.

- Autor.

Os resultados obtidos serão confrontados em pressupostos legais, o qual se espera indicar uma vertente sobre: "o que seria mais adequado à região?". Embora possa parecer tendencioso, o intuito que aqui se propõe, visa apresentar um parecer, seja este, a favor ou contra. 


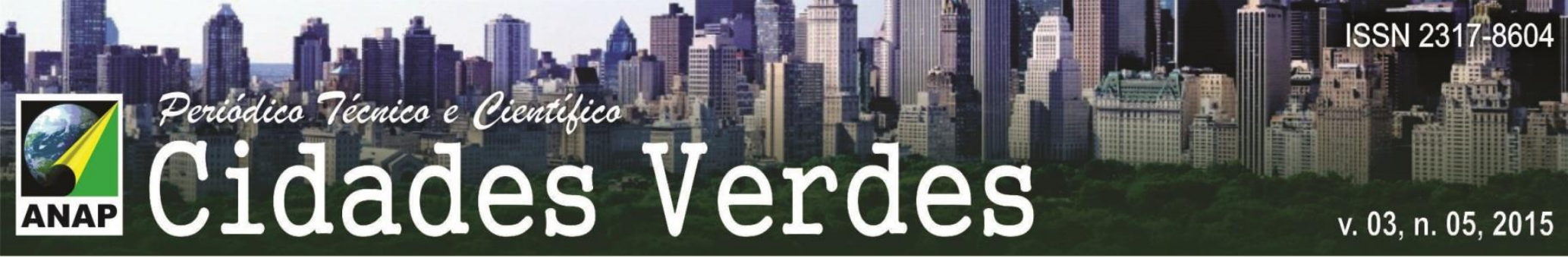

\section{HISTORIOGRAFIA}

Figura 3 - Compatibilização de imagens - Progressão histórica sobre a alternância entre uso e ocupação dos imóveis na Rua Augusta; e resumo histórico do Parque Augusta com os agentes sociais envolvidos (construtoras, ativistas e prefeitura).

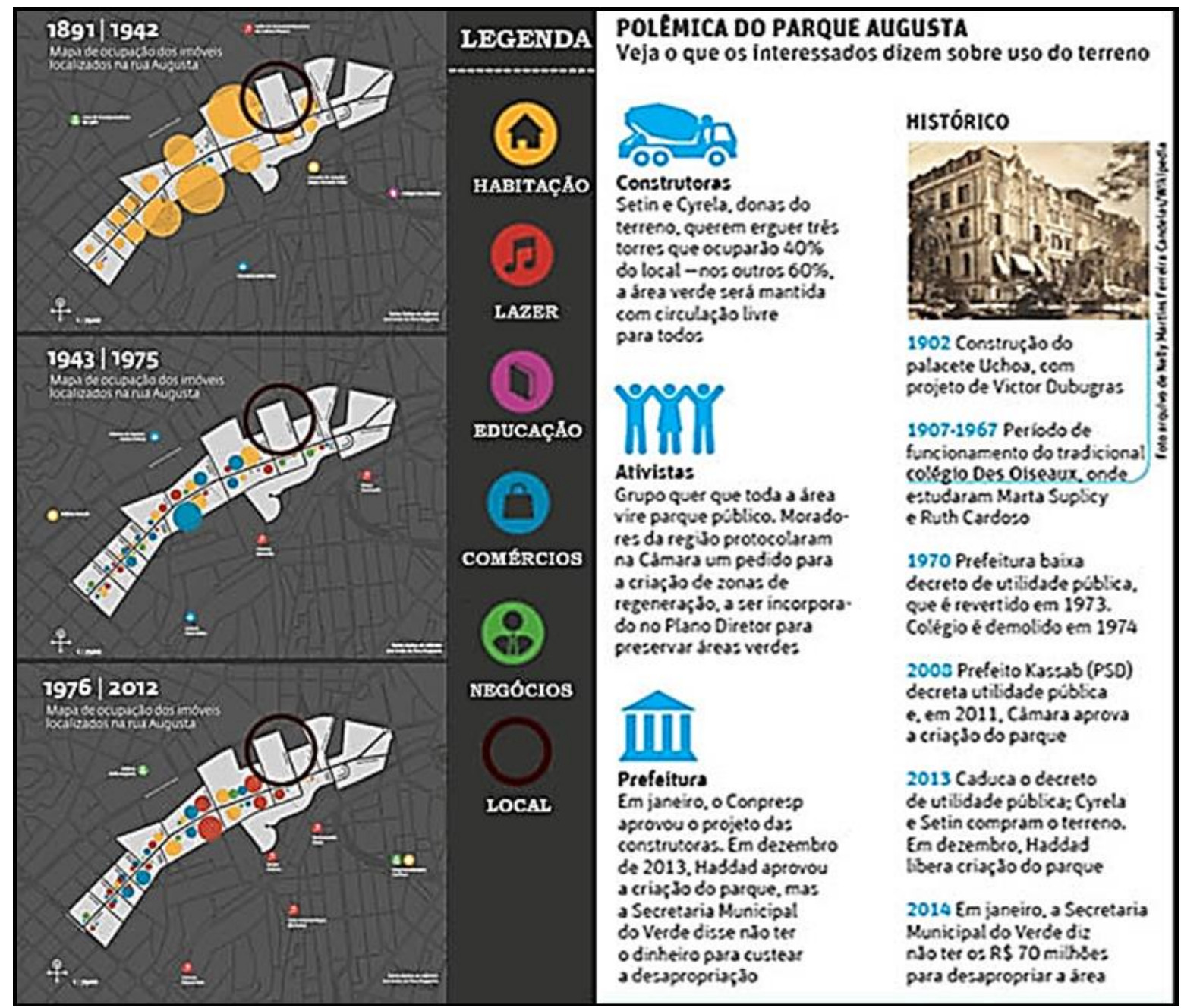

FONTE DAS IMAGES: Lado esquerdo (PISSARDO, 2013 p.24, 78 e 128); lado direito (Jornal - Folha de São Paulo, 08/04/2015). Edição: O próprio Autor.

Divulgado nos estudos de Felipe Pissardo (Figura 03 - lado esquerdo), a Rua Augusta é apresentada em três tempos, em primeiro momento tem-se o predomínio da ocupação residencial, motivado pelo loteamento das chácaras a região e arredores recebeu, sobretudo, imigrantes. Posteriormente, este cenário se reconfigura frente a díade "urbanização-industrialização" e setor comercial ganha força, problemas de trânsito e criminalidade colaboram para os residentes irem para 


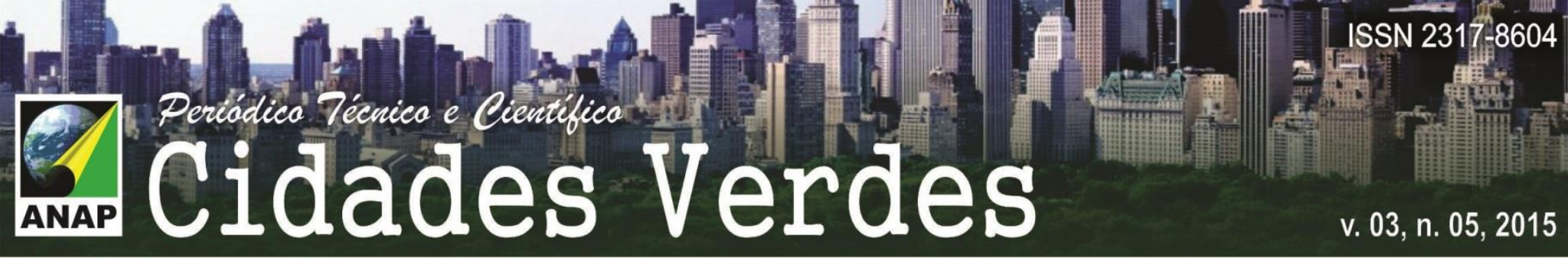

urbanística o caso do parque Gezi, onde as manifestações populares triunfaram sobre a especulação imobiliária, apesar de pouco substancial as referências dispostas pelos manifestantes e pela mídia eletrônica, foi necessário que esta pesquisa recorresse a outros padrões comparativos de análise para que se justificasse um comparativo pertinente com a Cidade de São Paulo, e não apenas por uma conquista territorial, portanto, através das imagens satélites (Figura 5 e 6) pré-dimensionadas em mesma escala, obteve-se o seguinte resultado urbano.

Figura 4 - Cidade de São Paulo, manchas verdes.

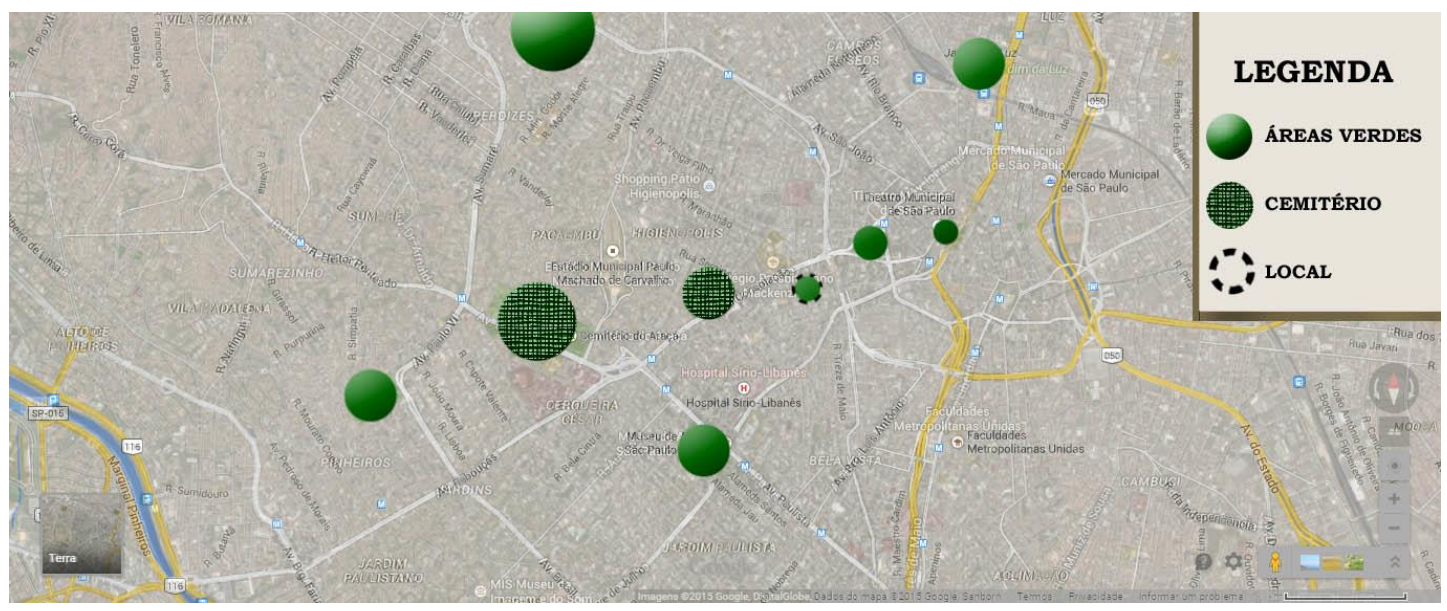

Fonte: GoogleMaps. (Escala original 1:1.000). Edição/ Elaboração: O próprio Autor.

Figura 5 - Cidade de Istambul, manchas verdes.

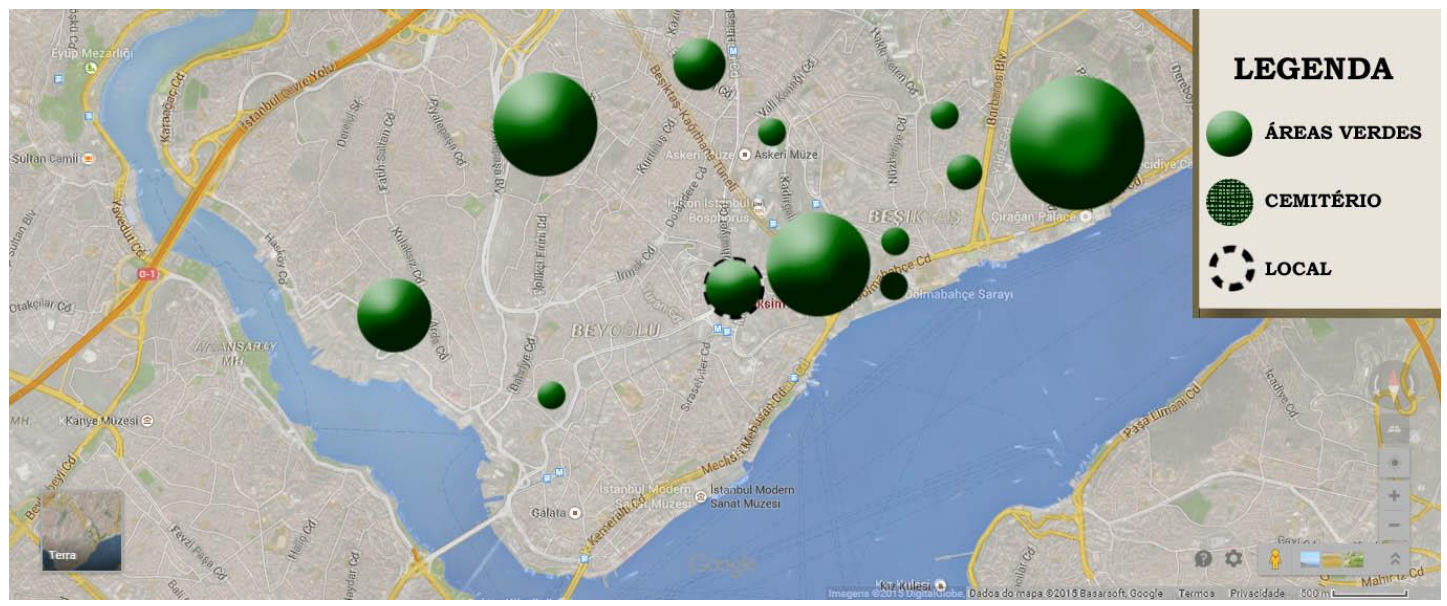

Fonte: GoogleMaps. (Escala original 1:1.000). Edição/ Elaboração: O próprio Autor. 
Alguns dados omissos entre as imagens: a cidade de São Paulo é duas vezes maior que a cidade de Istambul; a área total destas imagens satélite representam seis milhões de metros quadrados; a porção territorial analisada de Istambul foi somente do istmo; a massa arbórea da porção analisada de Istambul é cinco vezes maior que esta porção de São Paulo e a mesma proporção se repete na comparativa entre os parques; considerando os cemitérios, como mancha verde, representam 35\% do total que a cidade de São Paulo disponibiliza.

Por fim, tendo em mente ambos os posicionamentos, a Prefeitura intermedia este conflito de interesses e, neste contexto, a mesma já consolidou esta área, em fase de planejamento para conservação do verde enquanto parque urbano, contido dentro das diretrizes do Plano Diretor; entretanto, descarta a hipótese de um investimento milionário para aquisição desta área privada onde se encontra o parque, tendo em vista tantos outros investimentos urbanos. Portanto, a melhor alternativa foi aprovar o projeto, no estilo "meio a meio" que, neste caso, se tornou "60\% de área verde e 40\% construída".

A proposta dos ativista quer que toda a área seja recuperada e transformada em parque para o uso de todos. O projeto contempla pequenas intervenções como cinemateca, central de arte, ponto de reciclagem e captação de àgua da chuva (Figura 07). 


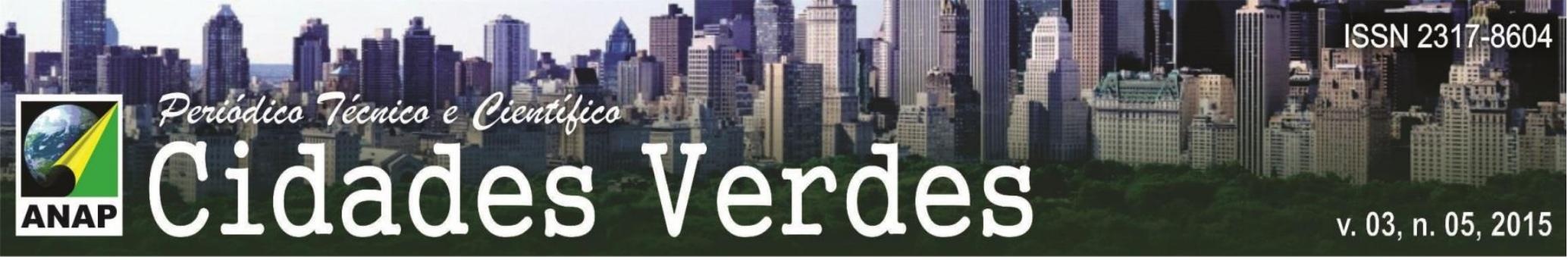

Figura 6 - Proposta Dos Ativistas

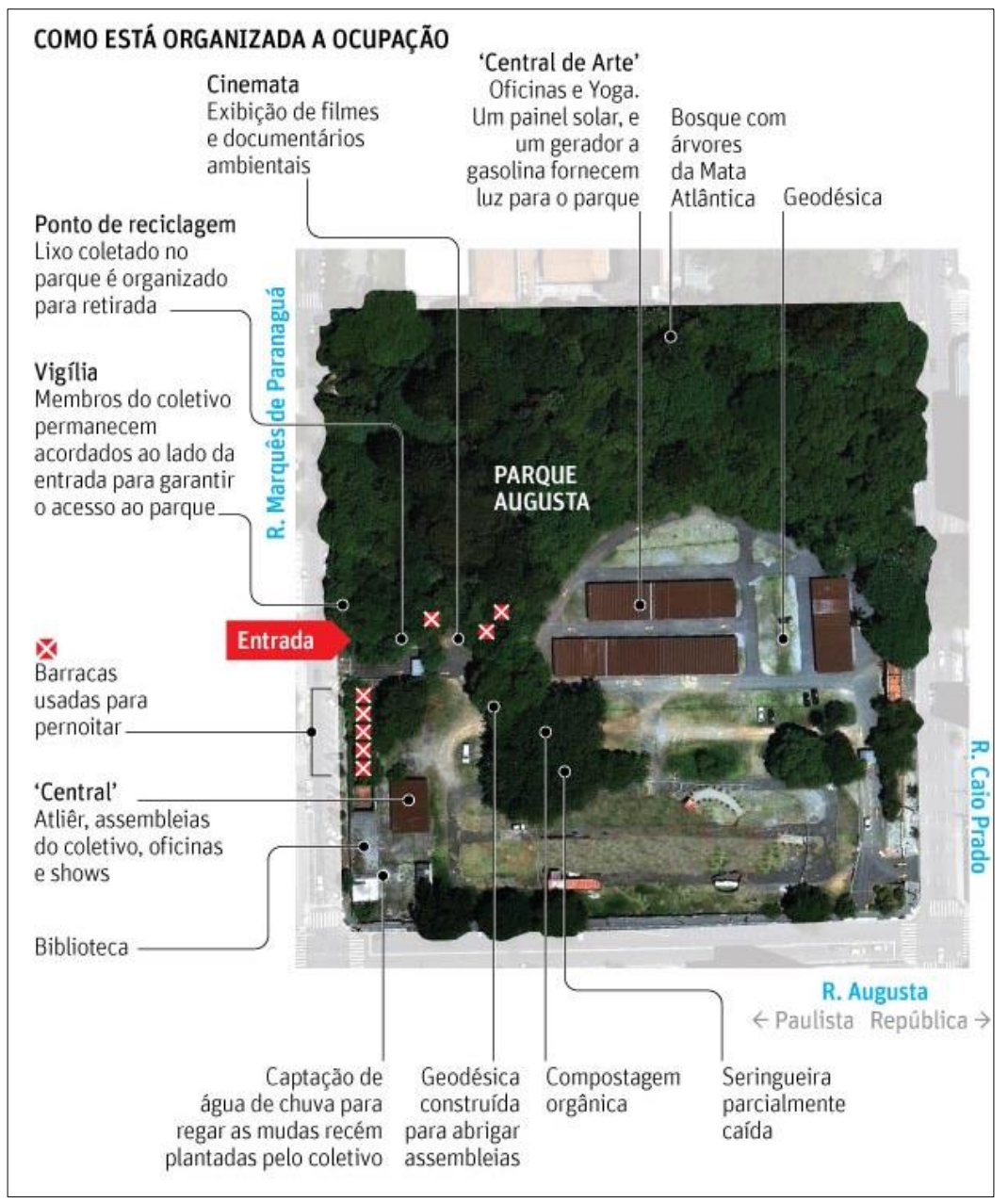

FONTE DA IMAGEM: Folha de S. Paulo, 04/03/2015.

\section{- A Legislação}

Segundo Correa (2000, p.8) a complexidade do espaço urbano mantém-se em constante mutabilidade e reflete a dinâmica de uma sociedade capitalista. $\mathrm{O}$ autor descreve que quem produz o espaço urbano são os agentes sociais, os quais levam a um constante processo de reorganização espacial, bem como a incorporação destas áreas para a renovação urbana. Esses agentes sociais que visam à apropriação de uma renda a partir da terra são: proprietários dos meios de produção e fundiários, promotores imobiliários, o Estado e grupos sociais excluídos.

Portanto, para se compreender e aplicar o pensamento de Correa ao local recorreu-se a legislação, pois o último parágrafo da alínea "a" do artigo $1^{\circ}$ do 
Decreto Municipal 10.766/1973 estava claro que não poderia ultrapassar $10 \%$ do desmatamento da área verde preservada existente, já no Decreto Municipal $15.645 / 1979$ retirou-se tal definição para flexibilizar as potencialidades edificantes. Com base nisso, grupos de grande influência sobre o Estado conseguem regulamentar juridicamente sua atuação. Posteriormente a Lei Municipal 10.365/1987 passou a proteger toda a área verde do parque. No Plano Diretor Estratégico (PDE) de 2004 foi classificada como área pública e reforçado no PDE de 2014 como Zona Especial de Preservação Ambiental (ZEPAM), entretanto, o impasse consiste no uso público da área e como poderá ser utilizada, visto que se encontra dentro de uma área privada.

Uma contrapartida possível de negociação junto à prefeitura é justamente através da classificação da área como ZEPAM, enquanto parque proposto, e quem sabe utilizar-se do instrumento urbanístico de negociação do potencial construtivo que, também, consiste na doação da área preservada, intermediada por uma desapropriação amigável, ou seja, por uma substituição equivalente do terreno, que teoricamente seria construída em outra, inclusive, passível de ampliação.

A desapropriação pela Prefeitura mostrou-se inviável pelos valores exorbitantes já levantados segundo os jornais à quantia ultrapassaria 70 milhões de reais. O atual prefeito, Haddad, já declarou que não optaria por esta indenização mesmo que disponibilizasse da verba, acredita-se que investimentos nas áreas de educação, saúde e transportes sejam prioritários.

\section{ALGUMAS CONSTATAÇÕES}

Quando analisados, os dados históricos revelam que desde a desocupação ou término das atividades do colégio, até o presente ano de 2015, passaram-se 46 anos, dentro deste período, a maior parte dos anos destinou-se à consistência conceitual de um fenômeno urbano que denegria a imagem da rua como um todo, gerando o desinteresse do local por todo o meio social, ou seja, ao contrário do que os críticos mais apressados disseram ou omitiram, o fato é de que ambos os setores, público e privado, somente voltaram sua atenção e deram sentido ao local, 
frente à valorização imobiliária da região que ocorreu nos últimos 10 anos. Este recorte temporal foi ratificado ao término da revisão bibliográfica nos dois principais acervos jornalísticos da Cidade, que demonstram cenas e produções do cotidiano. Obteve-se o seguinte produto (Tabelas 1 e 2):

Tabela 1: Relatório Geral do Jornal "O Estado de São Paulo”.

\begin{tabular}{cccc}
\hline Títulos & 2005 - 2010 & 2011 - 2015 & Total \\
\hline $\begin{array}{c}\text { N. de publicações e } \\
\text { percentual }\end{array}$ & $05(10.5 \%)$ & $43(89.5 \%)$ & $48(100 \%)$ \\
\hline Mesma autoria & 00 & 09 & $18 \%$ \\
Autorias diversas & 05 & 34 & $82 \%$ \\
\hline Finalidade (contra) & 00 & 08 & $17 \%$ \\
Finalidade (a favor) & 00 & 11 & $23 \%$ \\
Finalidade (neutro) & 05 & 24 & $60 \%$ \\
\hline
\end{tabular}

Fonte: http://acervo.estadao.com.br/. Tópico de Busca: "Parque Augusta” (acesso Abril de 2015).

Tabela 2: Relatório Geral do Jornal "Folha de São Paulo".

\begin{tabular}{cccc}
\hline Títulos & 2005 - 2010 & 2011-2015 & Total \\
\hline $\begin{array}{c}\text { N. de publicações e } \\
\text { percentual }\end{array}$ & $03(3.37 \%)$ & $86(96.63 \%)$ & $89(100 \%)$ \\
\hline Mesma autoria & 00 & 28 & $32 \%$ \\
Autorias diversas & 03 & 58 & $68 \%$ \\
\hline Finalidade (contra) & 00 & 21 & $24 \%$ \\
Finalidade (a favor) & 00 & 27 & $30 \%$ \\
Finalidade (neutro) & 03 & 38 & $46 \%$ \\
\hline
\end{tabular}

Fonte: http://acervo.folha.com.br/. Tópico de Busca: "Parque Augusta" (acesso Abril de 2015).

Nota-se que em ambos os acervos o percentual assemelha-se da seguinte forma: A maior atenção midiática ou de publicações, ocorreram nos últimos cinco anos, na qual as de mesma autoria destinam-se aos colunistas, ativistas e da própria construtora, enquanto as autorias diversas distinguem-se entre a opinião pública, que por sua vez, divergem em relação ao seu posicionamento. Outro dado complementar a este que se percebeu no decorrer da tabulação dos dados deve-se ao fato de que em relação à finalidade das posturas "contra, a favor ou neutra", 
referem-se especificamente a preservação da área em 100\% verde, ou seja, mesmo os que se mostraram "contra" defendem um percentual verde. A maior parte da opinião pública acredita ser desnecessário investimentos altos e pontuais na compra do terreno, tal posicionamento, hipoteticamente, é o mesmo apontado pela Prefeitura; além disso, em consonância a tais desígnios deve-se levar em consideração que a construtora tem como premissa projetual edificar $40 \%$ do terreno frente a $60 \%$ de preservação verde. Por fim, deve-se ressaltar que algumas publicações apresentam um caráter neutro seja por divulgações de eventos locais, como piquenique, shows, encontros e afins, bem como informes situacionais, que não tendem a nenhuma das vertentes "pró ou contra", além disso, constatou-se a prática de colunistas que apresentavam vantagens e desvantagens desta dialética em distintas periodizações, o que atribui ao autor, uma postura neutra, mas a matéria não.

Em uma visão sistêmica que, balizada pelo capital, na disputa deste território, os interesses público e privado, concorrem pela valorização imobiliária. Incorporada aos agentes sociais mencionados por Correa (2000), nesta disputa, fala-se de um acréscimo na valorização dos imóveis já existentes do entorno, em caso de não edificação, e da valorização do empreendimento local, em caso de consolidação, com ganhos para a construtora. Neste ponto, acredita-se que, a destinação da renda é o fator primordial entre os interesses.

Outro dado que se deve levar em consideração, refere-se ao percentual verde da Cidade, de fato são necessárias mais áreas. De acordo com Cavalheiro e Del Picchia (1992), os quais apresentaram a existência do índice de: $12 \mathrm{~m}^{2}$ de área verde/habitante; este conceito foi arraigado e difundido no Brasil e atribuído pela ONU que o considerou ideal. Contudo, deve-se levar em consideração que o centro é bastante verticalizado, mas não adensado em termos de residentes (SOMEKH, 2014, p.19), ou seja, fora do horário comercial a Cidade perde parte de sua vitalidade.

Hipoteticamente, o empreendimento pretendido tem como público alvo os jovens, que visam otimizar o tempo aproximando certas funções, sobretudo, no que diz respeito ao deslocamento e permanência - fala-se em residir, trabalhar e estudar 
- além do maior aproveitamento do tempo livre. Em hipótese, o uso do automóvel para este público torna-se dispensável ou minimamente utilizável. Ainda em relação ao verde, não seria a totalidade do lugar que resolveria esta carência urbana, mas seria um começo. Alternativas inspiradas nos exemplos internacionais como Pocket Parks (praças de bolso), se mostrariam mais significativos e eficientes, para suprir estes $40 \%$ ocupado pela construtora, nos terrenos ociosos ao longo das ruas circunvizinhas, além de gerar maior vitalidade em todos os sentidos se aplicados em diversos pontos das quadras, ou seja, uma descentralização ou desfragmentação verde.

\section{RESULTADOS E CONCLUSÕES}

O ativismo urbano esta em ascensão, sobretudo, pelas redes sociais ou de compartilhamento. É nesse contexto que diversos movimentos ganham repercussão midiática e, em São Paulo, grupos ativistas organizam-se de forma colaborativa para ocupar, reivindicar e transformar espaços estéreos em ambientes que possam agregar pessoas. Dos objetivos fundamentais, tratando especificamente da área do parque Augusta, duas vertentes: a do capital e a do lazer.

Levando em consideração as condicionantes do entorno e as preexistências, manter a área em conformidade à situação atual, não se alcançaria a qualidade desejada de parque, enquanto espaço de convívio, sendo fundamental as remodelações ou intervenções paisagísticas, ou seja, criar espaços guiados e delimitados por nichos que, ainda sim, poderiam gerar insegurança na ordem pública, a mesma sensação é vivenciada nas praças da República, Trianon, Roosevelt e entre outras. As propostas da implantação de um ou mais edifícios que deixam o térreo livre e criam marquises de uso público, incluindo a mescla edificante entre comércios e residências, ao estilo COPAN, mostra-se muito mais adequada para a implantação de um parque circunvizinho para uso público, pois atrairia mais usuários devido à segurança. Neste ponto, o discurso assemelha-se ao da jornalista Jane Jacobs, que nos parece bastante assertivo ao discorrer sobre as "atribuições 
